\title{
Experimental infections of Atlantic salmon Salmo salar with Spironucleus barkhanus
}

\author{
Fu Ci Guo, Patrick T. K. Woo* \\ Department of Zoology, University of Guelph, Guelph, Ontario N1G 2W1, Canada
}

\begin{abstract}
Atlantic salmon Salmo salar L. (Salmonidae) were experimentally infected with Spironucleus barkhanus (Diplomonadida: Hexamitidae). Parasites were found in the blood 1 to $8 \mathrm{wk}$ after infection, after which they disappeared from the blood and were found mainly in the internal organs (e.g. spleen and liver), eye socket or muscles. Mortality (38 out of 40 infected fish) occurred when fish had lesions in internal organs and/or on the body surface. Uninfected fish cohabiting with infected fish became infected after $4 \mathrm{wk}$, indicating direct transmission. There was no difference in susceptibility to spironucleosis between 3 different families of Atlantic salmon. All families developed the disease with a similar pattern of parasitaemia in the blood, similar clinical signs and gross pathology, and with very high mortality (29 out of 30 ). Clinical signs of systemic spironucleosis may include anemia, skin blisters, muscle ulcerations or unilateral exophthalmia. Gross pathologies include hemorrhaging of internal organs, splenomegaly or deformed (globulated) spleen, or granulomatous lesions in the spleen and liver.
\end{abstract}

KEY WORDS: Spironucleus barkhanus - Systemic spironucleosis · Salmo salar · Transmission · Clinical signs $\cdot$ Mortality

\section{INTRODUCTION}

Severe systemic infections by a diplomonad flagellate, Spironucleus barkhanus (Hexamitidae), were reported in postsmolts (200 to $250 \mathrm{~g}$ ) and adult (4 to $5 \mathrm{~kg}$ ) Atlantic salmon Salmo salar L. cultured in seawater cages near Alta in northern Norway (Mo et al. 1990, Poppe et al. 1992, Poppe \& Mo 1993). There was a similar outbreak of systemic spironucleosis in chinook salmon Oncorhynchus tshawytscha in British Columbia, Canada (Kent et al. 1992). These flagellates morphologically (under light microscope) resemble Hexamita salmonis, which is commonly found in the intestine of salmonids reared in freshwater. Infections by H. salmonis in salmon fry range from sub-clinical to clinical anorexia, emaciation, slow growth and mortality (Moore 1922, Davis 1926, Kulda \& Lom 1964, Sano 1970, Becker 1977, Ferguson 1979, Uldal \& Buchmann 1996, Tojo \& Santamarina 1998). Systemic infections by diplomonad flagellates have also been reported in Siamese fighting fish Betta splendens (Ferguson \& Moccia 1980) and cichlids, and may be responsible for the hole-in-the-head disease (Woo \& Poynton 1995, Paull \& Matthews 2001) and lip tumor (Poynton et al. 1995).

It was hypothesized that wild Arctic char Salvelinus alpinus was the source of infection for the outbreak of systemic spironucleosis in cage culture Atlantic salmon in Norway (Sterud et al. 1998) and that Spironucleus barkhanus had an intracellular stage in farmed Artic char with no apparent disease (Sterud et al. 2003). The typical clinical signs and gross pathology of spironucleosis in naturally infected Atlantic salmon include lesions in the musculature, liver, spleen, kidney (Poppe et al. 1992) and exophthalmia (Poppe \& Mo 1993).

The present research was initiated since there are no published reports on experimental infection with Spironucleus barkhanus in salmonids. This study focuses on the course of infection, on the transmission between fish, and on the susceptibility of families of Atlantic salmon to infection. 


\section{MATERIALS AND METHODS}

Parasites. The strain of Spironucleus barkhanus was obtained from the American Type Culture Collection (Rockville, Maryland, USA), ATCC 50377 (originated from muscle abscess in Atlantic salmon Salmo salar from Vesteraalen, Norway) and subsequently maintained in our laboratory by passages in Atlantic salmon.

The parasite used in the 'course of infection' study came from the right eye cavity of an experimentally infected Atlantic salmon 12 wk post infection (wpi). The bulging eyeball was removed and the eye socket washed with phosphate buffered saline (PBS, pH 7.2). The number of parasites was determined using a hemocytometer (Improved Neubauer, Hausser Scientific) and fish were infected by intraperitoneal (i.p.) injection. The parasite used in the 'transmission by cohabitation' study was from the right eye socket of another fish (14 wpi), while the parasite for the 'susceptibility of 3 full-sib families' study was from the left eye socket of a 9 wpi fish.

Fish maintenance, blood sampling and post mortem. Hatchery-raised juvenile Atlantic salmon were obtained from either the Ontario Ministry of Natural Resource (OMNR fish; Stouffville, Ontario) or the Atlantic Salmon Broodstock Development Program (ASBDP fish; St. Andrews, New Brunswick), and raised in the laboratory to sub-adult size (200 to $300 \mathrm{~g}$ ). The fish were kept in circular fiber glass tanks (120 l) with continuous aeration and flow-through well water (flow rate: $21 \mathrm{~min}^{-1}$ ). The water temperature was maintained at 10 to $11^{\circ} \mathrm{C}$ throughout the experiment, and the fish were held under a 12:12 h light:dark photoperiod and fed daily to satiation with commercial salmon feed (Point No. 5, Martin's Feed Mills).

Fish were anesthetized with 300 ppm 2-phenoxyethanol (Acrco Organics) solution to stage IV of anesthesia (total loss of equilibrium; McFarland 1960) before blood sampling. A heparinized disposable needle (25G, $5 / 8$ ) and disposable plastic syringe $(1 \mathrm{ml})$ were used to withdraw blood $(0.1$ or $0.15 \mathrm{ml})$ from the caudal vein. Blood was kept on ice until parasitemia and packed cell volume were determined. Fish were returned to fresh well water for recovery after they were examined for clinical signs of disease or any other abnormality.

Dead fish were removed from the tanks, and underwent post mortem examinations. They were examined for external and internal lesions and for parasites in mucus, lesions, eye sockets, peritoneal cavity and internal organs (e.g. liver, spleen, kidney, heart, gall bladder, intestine, pyloric caeca).

Techniques for parasite detection and quantitation. Three techniques - Wet Mount Examination (WME), Hematocrit Centrifuge Technique (HCT; Woo 1969) and
Hemocytometer (HCM; Archer 1965) — were used for the detection and quantitation of parasites in the blood. WME was used for mucus detection; WME and HCM were used for tissues and organs (Guo \& Woo 2004).

Packed cell volume (PCV) and spleen volume (SV). PCV was determined using a hematocrit centrifuge (Archer 1965). The spleen was removed from dead fish and its volume measured in a $10 \mathrm{ml}$ glass measuring cylinder (with accuracy of $0.1 \mathrm{ml}$ ) by immersing it in $3.0 \mathrm{ml}$ of cold PBS. The increased volume (ml) was recorded as SV.

Experimental design. Course of infection: Atlantic salmon (15 OMNR fish) weighing 271.0 $\pm 58.9 \mathrm{~g}$ (mean $\pm \mathrm{SD}$ ) were individually marked by peritoneal insertion of a PIT (Passive Integrated Transponder) tag (AVID Microchip I.D. Systems) several months prior to the start of the experiment. The fish were randomly separated into 3 groups: 5 fish as control in one tank, 5 fish as high dose group (HD) in a second tank and a further 5 fish as low dose group (LD) in another tank. The HD group were i.p.-injected with 100000 Spironucleus barkhanus in $0.2 \mathrm{ml}$ of PBS, the LD group with 50000 $S$. barkhanus in $0.2 \mathrm{ml} \mathrm{PBS}$, and the control group with $0.2 \mathrm{ml}$ of PBS without the parasite. Blood samples were taken from all fish 1 wk before i.p. injection and weekly after the infection.

Transmission by cohabitation: Atlantic salmon (12 OMNR fish) weighing 71.2 $\pm 15.1 \mathrm{~g}$ (mean $\pm \mathrm{SD}$ ) were individually PIT tagged. Four fish were randomly selected and each fish was i.p. injected with 60000 Spironucleus barkhanus in $0.1 \mathrm{ml}$ PBS. The 8 control fish (uninfected) were i.p. injected with $0.1 \mathrm{ml}$ PBS. Infected and uninfected fish were held in the same tank. Blood samples were taken $1 \mathrm{wk}$ before injection and weekly after the injection. Uninfected fish were always bled $4 \mathrm{~d}$ after the infected fish to minimize the risk of artificial infection by the needle wounds. Mucus from fish was gently scraped from the skin near the lateral line using a wooden stick, mixed with a drop of cold PBS and examined under a light microscope.

Susceptibility of 3 full-sib families: Atlantic salmon (60 ASBDP fish) weighing $263.9 \pm 54.0 \mathrm{~g}$ (mean $\pm \mathrm{SD}$ ) were used. Twenty fish from each of 3 families (A, B and $C$ ) were used, with 10 as a control group in one tank and 10 as an infected group in another tank. All fish were individually PIT tagged. Fish from the infected group were injected with 30000 Spironucleus barkhanus in $0.2 \mathrm{ml}$ PBS, while the fish from the control group received $0.2 \mathrm{ml}$ PBS. Blood samples were taken weekly for parasite detection and quantitation as previously described.

Statistical analysis. Fish weight, packed cell volume and spleen volume with relation to body weight were analyzed by ANOVA for statistical significance among each group and between control and infected groups. 


\section{RESULTS}

\section{Course of infection (Fig. 1)}

At 1 wpi, Spironucleus barkhanus was detected in the blood of 3 out of the 10 infected fish using HCT (1 in HD group, 2 in LD group). At 2 wpi, 4 were positive ( 2 in HD group, 2 in LD group) while WMEs were still negative for $S$. barkhanus. At $3 \mathrm{wpi}, 8$ fish were positive (5 in HD group, 3 in LD group) using WME and HCT. By 4 wpi, all 10 fish were positive and parasitemias in both the LD and HD groups were highly variable (ranging from 20 to $118000 \mathrm{ml}^{-1}$ ). By 5 and 6 wpi, 3 and 6 out of 10 fish became negative for S. barkhanus in the blood, and 1 fish (LD group) died of spironucleosis. By $7 \mathrm{wpi}$, only 2 fish had detectable parasites in the blood and 2 fish had died of spironucleosis. At 8 wpi, only 1 fish had $S$. barkhanus and 1 fish died. From 9 wpi onwards, $S$. barkhanus was not detected in the blood of all fish. During the bloodphase stage of the disease, 4 out of 10 fish died and at 12 wpi, 3 more fish died. Parasites were found in the muscle lesions, eye sockets, abdominal cavity and internal organs (liver, spleen). At $14 \mathrm{wpi}$, another fish died and $S$. barkhanus was found in the liver (parasitemia $\left.3.3 \times 10^{6} \mathrm{~g}^{-1}\right)$, spleen $\left(4.8 \times 10^{6} \mathrm{~g}^{-1}\right)$ and serous ascites $\left(4.6 \times 10^{6} \mathrm{ml}^{-1}\right)$. At $21 \mathrm{wpi}, 1$ fish died following the rupture of a 7 wk old dorsal blister, about $5.5 \times$ $10^{6} \mathrm{ml}^{-1}$ of the parasites were found in the squashed tissue from the blister. One fish recovered from the $S$. barkhanus infection and survived till the termination of experiment. At necropsy this fish had no parasites either externally or internally but the fish had a small globulated spleen.

Mortality in all of the 9 fish that died during the 22 wk course of infection was caused by Spironucleus barkhanus, because the parasites were found either in the blood, tissues or organs. None of the 5 fish in the control group died or were infected with $S$. barkhanus.

\section{Clinical signs}

The clinical signs of infection were fluctuating PCVs (anemia), unilateral exophthalmia, abdominal distension and skin blisters, lesion and ulceration.

Fluctuating PCVs (Fig. 2): Blood samples were taken from all fish 16 times over $21 \mathrm{wk}$. Weekly blood sampling reduced PCV from 0 to $4 \mathrm{wk}$ in the control group and it stayed relatively stable after $4 \mathrm{wk}$. The PCVs of the infected group also dropped (but were not statistically different to the control, $\mathrm{p}>0.05$ ) from 0 to $4 \mathrm{wk}$, with a slight recovery at $6 \mathrm{wpi}$. PCV decreased again and leveled off from 7 to $9 \mathrm{wpi}$, and

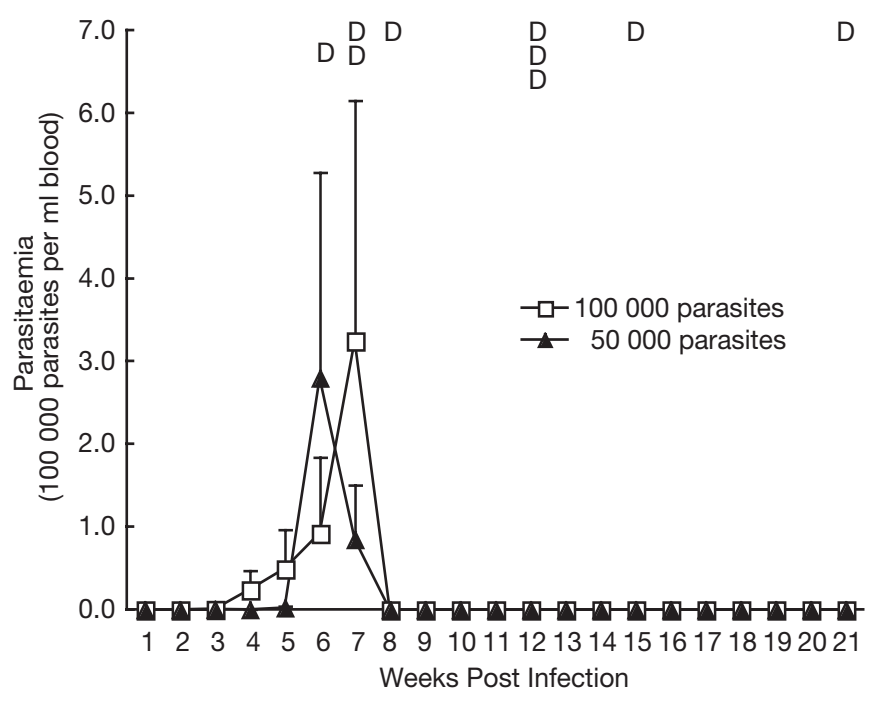

Fig. 1. Parasitaemia of Spironucleus barkhanus in Atlantic salmon. HD: high dose group, 100000 parasite per fish; LD: low dose group, 50000 parasite per fish; data are means \pm SD. D: death

then decreased further at 10 wpi. Significant differences (ANOVA, p < 0.05) between the means of PCVs of the control and infected groups occurred at 5, 9 and 10 wpi. These differences indicate that Spironucleus barkhanus caused anemia in the infected fish. Comparisons of PCVs between the control and infected groups were not analyzed statistically after 14 wpi because there were only 2 fish left in the infected group.

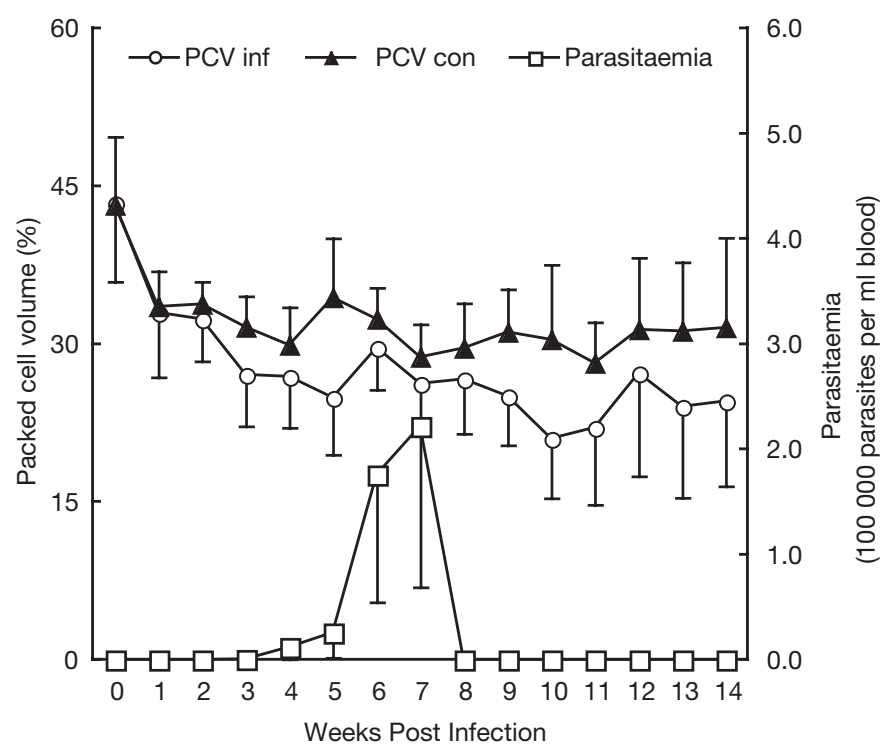

Fig. 2. Packed cell volume (PCV) of 5 control fish (con) and 10 infected fish (inf) with average parasitemia (data are means $\pm \mathrm{SD}$ ) 


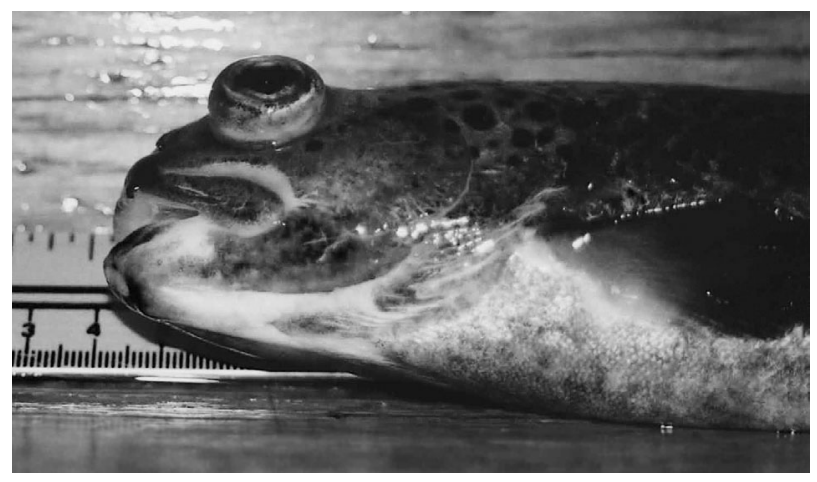

Fig. 3. Salmo salar. Unilateral exophthalmia of Atlantic salmon

Unilateral exophthalmia (Fig. 3): A HD group fish had unilateral exophthalmia (left eye) at 7 wpi. The lens became opaque and the fish died 1 wk later with high numbers $\left(3.6 \times 10^{6} \mathrm{ml}^{-1}\right.$ squashed eye tissue) of Spironucleus barkhanus in the eye cavity; however, no parasite was found in the right eye or in the blood. The right eye exophthalmia of a LD group fish started at $9 \mathrm{wpi}$; the unilateral exophthalmia lasted $3 \mathrm{wk}$ and the fish died at 12 wpi with high numbers of $S$. barkhanus in the eye socket, among areas of extrinsic muscles and optic nerve, but with low numbers in the vitreous humor. The left eye was normal and no parasite was detected.

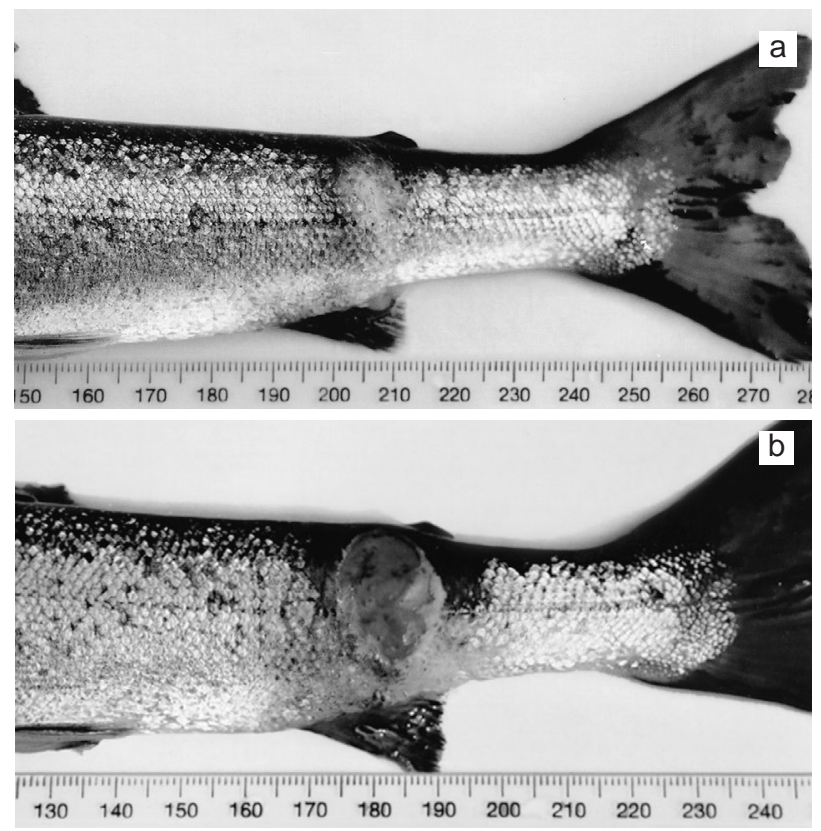

Fig. 4. Salmo salar. From (a) blister to (b) ulceration on the same Atlantic salmon
Abdominal distension: During 10 to $11 \mathrm{wpi}, 2$ fish (HD group) showed a slightly distended abdomen; one of the fish died at 12 wpi, with high numbers of Spironucleus barkhanus found in the serous ascites. Its spleen was enlarged (about 2 times the normal size) and there were hemorrhages in the pyloric caeca. The other fish died at 14 wpi, with high numbers $\left(4.6 \times 10^{6} \mathrm{ml}^{-1}\right)$ of $S$. barkhanus in the serous ascites, and the liver and spleen were found to have focal white nodules.

Skin blisters, muscle lesion and ulceration: One fish (LD group) had a blister on the left side of the tail

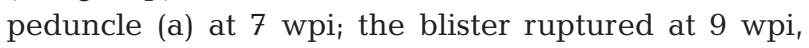
exposed caseous tissue (Fig. 4b), and the fish became listless and died. High numbers $\left(8.1 \times 10^{6} \mathrm{ml}^{-1}\right.$ excised and squashed skin and muscle tissues) of Spironucleus barkhanus were found at the ulcer area. At 13 wpi, another LD group fish developed a blister below the dorsal fin and above the right lateral line; the blister grew to a noticeable bump (approximately $3.5 \times$ $1.5 \mathrm{~cm}$ ) at $17 \mathrm{wpi}$, and the fish died after the blister ruptured at $20 \mathrm{wpi}$. High numbers of the parasite were found from the ulceration.

\section{Other gross pathology}

Five fish died with no obvious external lesions, but internal lesions were found, such as whitish to yellowish granulomatous nodules in the liver and spleen (Fig. 5) or hemorrhages of the internal abdominal wall. High numbers of parasites were recovered from the lesion areas of the liver and spleen (1.4 and $4.8 \times$ $10^{6} \mathrm{~g}^{-1}$ of respective tissues).

\section{Transmission by cohabitation}

For the 4 fish that were experimentally inoculated with Spironucleus barkhanus, the parasites were found in the blood from 1 to $6 \mathrm{wpi}$, in the skin lesion of one infected fish at $4 \mathrm{wpi}$, and in the mucus of an infected fish with no obvious skin lesions at 9 and 10 wpi. One infected fish developed unilateral exophthalmia at $13 \mathrm{wpi}$, with parasites on the surface of the protruding eyeball, and 2 fish developed tail lesion and ulcers. Among the 8 cohabiting uninoculated fish, 1 was positive with parasites in the blood at $5 \mathrm{wk}$ post cohabitation (wpc). A total of 4 uninoculated fish became infected after $9 \mathrm{wpc}$, and the parasite was in the blood for 4 to 6 wk. One fish developed right exophthalmia at $13 \mathrm{wpc}$ and 2 fish had tail lesions. The course of infection in fish infected by i.p. injection or by cohabitation followed a similar pattern: a 4 to $6 \mathrm{wk}$ blood phase, followed by tissue phase with ulcerated skin, granulomatous lesions in internal organs or exophthalmia and mortality. 

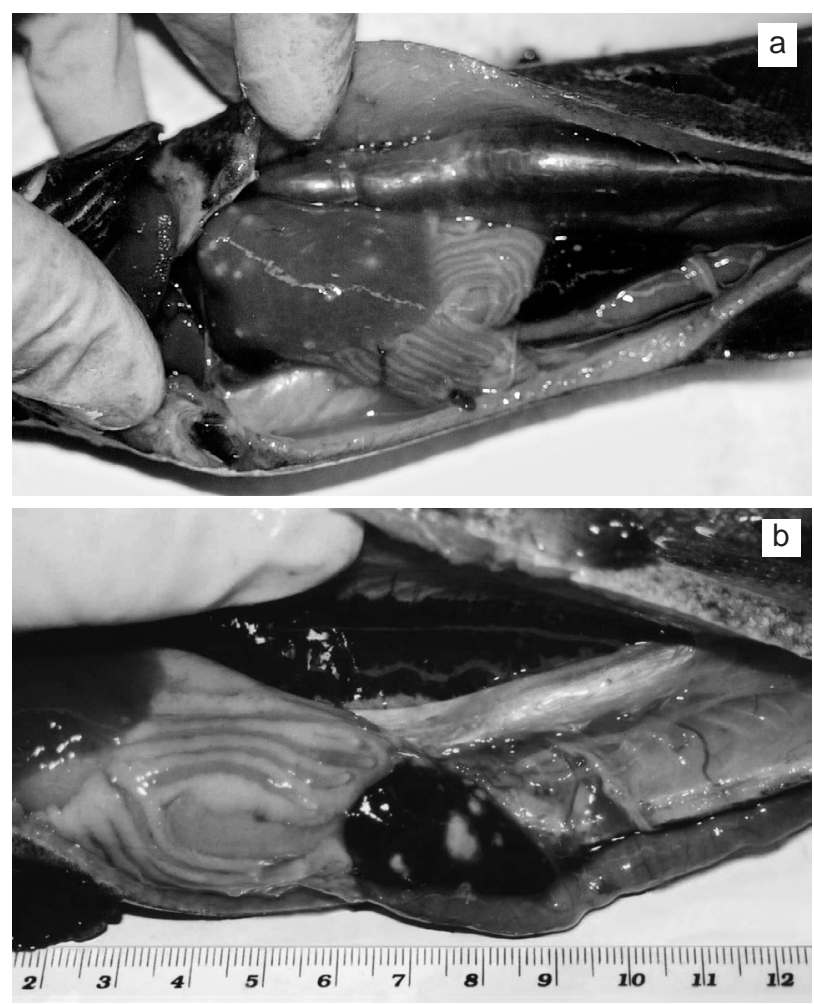

Fig. 5. Salmo salar. Yellowish nodules in the (a) liver and (b) globulated spleen in Atlantic salmon

\section{Susceptibility of 3 full-sib families}

All 30 injected fish had Spironucleus barkhanus in the blood at 1 wpi and parasitemias peaked at 2 wpi, with $42603 \pm 32688,14750 \pm 9340$ and $22850 \pm$ $8358 \mathrm{ml}^{-1}$ blood (mean $\pm \mathrm{SE}$ ) for Families A, B and C, respectively. Parasitemias decreased to near zero in Families A and B at 3 wpi and at 4 wpi in Family C. Family A had a second small peak at 4 wpi. At 5 wpi, $S$. barkhanus were not found in the blood of all fish, except for 1 fish in Family A which had a parasitaemia of $4.1 \times 10^{6} \mathrm{ml}^{-1}$ blood (Fig. 6). There were petechial hemorrhage spots on the ventral body surface anterior to the anus in some fish of each family at $7 \mathrm{wpi}$; $S$. barkhanus were found in mucus scrapings from these red spots from 11 fish. Mortality started at 7 wpi, peaked at 9 wpi, and by 11 wpi 29 out of 30 fish had died (Fig. 6). Post-mortem examination on dead fish showed splenomegaly. The spleens were enlarged over 3 times compared to the control groups; there was no statistical difference $(p>0.05)$ in spleen size between the 3 infected families. Of the fish that died at 10 to 11 wpi, about one-third in each family had a white layer of connective tissue covering the spleen and lower intestines (Fig. 7). PCV values between the
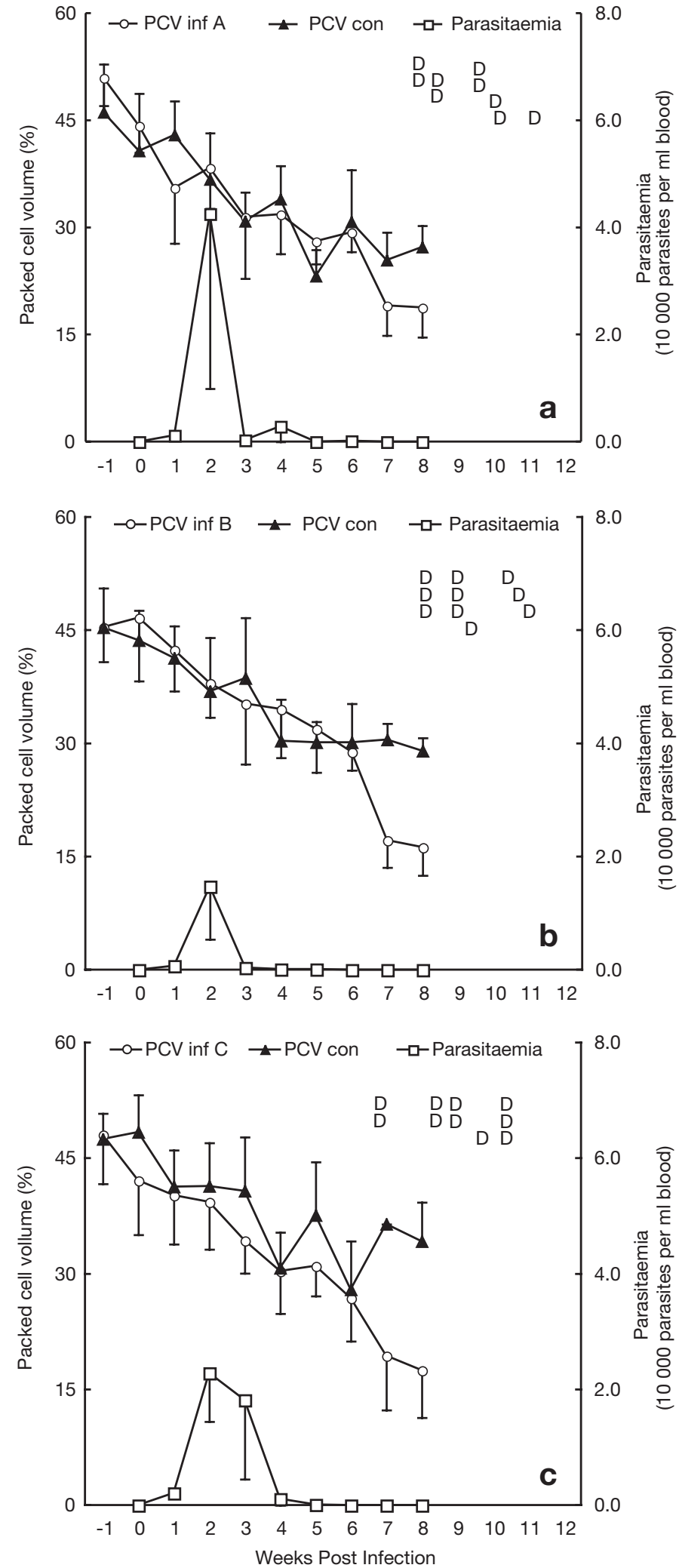

Fig. 6. Salmo salar. Parasitaemia, packed cell volume (PCV) and mortality in Families (a) A, (b) B and (c) C of Atlantic salmon. D: death 


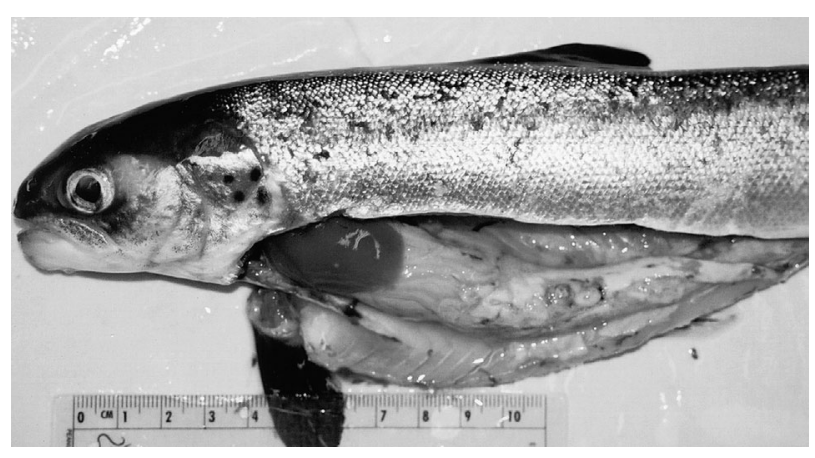

Fig. 7. Salmo salar. Spleen covered by a layer of white tissue in Atlantic salmon infected (late stage) with Spironucleus barkhanus

control and infected group within each family showed no significant difference from 1 to $6 \mathrm{wpi}$, but significant differences $(\mathrm{p}<0.05)$ at 7 and $8 \mathrm{wpi}$, indicating that the infected fish were anemic. Clinical signs associated with systemic spironucleosis (such as exophthalmia and severe skin ulcers) that were observed in the previous 2 experiments were not seen in the 3 families.

None of the 10 fish in each control group died or were infected with Spironucleus barkhanus.

\section{DISCUSSION}

Systemic Spironucleus infections have been reported in salmonids as well as cichlids, namely angel fish Pterophyllum scalare and discus Symphysodon discus, and are possibly associated with hole-in-thehead disease (Woo \& Poynton 1995, Paull \& Matthews 2001) and lip tumor (Poynton et al. 1995). The causative agent Spironucleus vortens was not only found in head lesions and lip tumor, but also in the liver, spleen, kidney and intestine. Large numbers of Spironucleus vortens were found in both the head skin lesions (holes) and internal organs; this was quite different from our present study on Atlantic salmon in which fish had high numbers of Spironucleus barkhanus in either the tail (skin and muscles) lesions, bulging eyeballs or lesions in internal organs (spleen or liver), but were not inside the intestine. In addition, our study showed that systemic spironucleosis in Atlantic salmon had a distinct blood and tissue phase. Paull \& Matthews (2001) did not record S. vortens in the blood or heart of cichlids, while Molnar (1974) and Ferguson \& Moccia (1980) found the parasites in the blood, heart and other internal organs in other ornamental fishes.

Atlantic salmon were infected with Spironucleus barkhanus through i.p. injection and systemic infec- tions were seen in fish maintained in freshwater. The disease caused by $S$. barkhanus in fresh water (present study) and in seawater net-pens (Poppe et al. 1992) was very similar in both its clinical signs and gross pathology. Poppe et al. (1992) suggested that spironucleosis in Atlantic salmon might be caused by a marine species of Spironucleus. The transmission by cohabitation experiment (Kent et al. 1992) demonstrated that an undescribed Spironucleus which caused systemic infection in chinook salmon Oncorhynchus tshawytscha could be transmitted in both fresh- and seawater and an in vitro experiment showed that the parasite survived longer in seawater than freshwater. Kent et al. (1992) also suggested that the parasite was a marine organism. Our present cohabitation experiment indicated that $S$. barkhanus could also survive in freshwater and that direct transmission is possible. The parasite was detected in the mucus of a 9 wpi fish with no obvious skin lesions and in the skin lesion of a $4 \mathrm{wpi}$ fish. It is likely that the parasites on the fish body surface are protected from osmotic stress by mucus. Further study is needed to investigate the mechanisms involved for the emergence of the parasite and its survival in freshwater. The mechanisms may be similar to those in salmonid cryptobiosis (Woo 2003).

In the present study, parasites appeared in the blood during the first week of infection and remained for up to $8 \mathrm{wk}$ before they were localized in the organs, skin and muscles. They appeared as white nodules in the spleen, liver, skin ulcers and exophthalmia eyeball. The first wave of mortality occurred at the late stage of the blood phase, and if the fish survived some of them would develop exophthalmia or skin lesions followed by a second wave of mortality. Many fish died even when there were no detectable parasites in the blood, and this would make clinical diagnosis unreliable if it was based solely on blood examination. Furthermore, the gross pathology in internal organs (granulomatous lesions in the spleen and liver) is similar to other necrotizing lesions (e.g. Bacterial Kidney Disease), and the presence of Spironucleus barkhanus in internal organs (not just in blood) must be detected to confirm an outbreak.

In our study, 9 out of 10 fish died in the 'course of infection' study, and 29 out of 30 fish died in the 'susceptibility of 3 full-sib families' study. These are very similar to the mortality figures from natural infections reported in Norway. Sterud et al. (2003) reported that the prevalence of infection in Atlantic salmon was very high, with about $100 \%$ mortality in some affected cages.

Anemia was observed in the current study; although it was not consistent during blood phase, it was consistent in tissue phase (based on 40 fish, 'course of infection' study and 'susceptibility of 3 full-sib families' 
study). Anemia found in salmonids with Crytobia salmonsitica infections (a pathogenic hemoflagellate) was caused by the hemolytic components of the parasite and formation of immune complexes on red blood cells (Thomas \& Woo 1988). Anemia in gold fish Carassius auratus infected with Trypanosoma danilewskyi was because of hemolysis and hemodilution due to increased blood volume (Islam \& Woo 1991). Anemia in chinook salmon infected with an undescribed Spironucleus species was found to be in part due to hemodilution and hemorrhage (Kent et al. 1992). Systemic Spironucleus infection in Atlantic salmon exhibits splenomegaly and focal granulomatous lesions in the spleen, liver and skin ulcers, which suggest that the anemia (at tissue phase) may have been due in part to hemorrhage.

Obvious kidney lesions were not observed in over 40 infected Atlantic salmon, which is in contrast to the report of Poppe et al. (1992), who found prominent granulomatous lesions in the posterior part of the kidney (2 out of 9 naturally infected fish). Unilateral exophthalmia were observed rather consistently in our study (except in the 'susceptibility of 3 full-sib families' study, in which most fish died before exophthalmia developed). Although exophthalmia was reported previously, it was not specified as unilateral or bilateral. Naturally infected Atlantic salmon developed blisters which developed into abscesses and boils in large Atlantic salmon (4 to $5 \mathrm{~kg}$ ), but boils were not seen in postsmolts of 200 to $250 \mathrm{~g}$ salmon (Poppe et al. 1992). In our current study, severe blisters and ulcers were observed on the body surface of postsmolts (ranging from 52 to $320 \mathrm{~g}$ ) of OMNR fish; however, abscesses and ulcers were not seen on ASBDP fish in the 'susceptibility of 3 full-sib families' study because the fish died before ulcers developed. Consequently, these external lesions are only in Atlantic salmon during the tissue phase of the disease.

Different parasite inocula (100000, 50000 or 30000 parasites per fish) produced similar onset and disease patterns (a blood and a tissue phase) and all the Atlantic salmon that were inoculated with the parasite were infected and developed disease. A total of 44 Atlantic salmon were infected with 30000 to 100000 Spironucleus barkhanus; the parasitemias were different in the 3 experiments during the blood phase and were highly variable among fish in the same experiment (e.g. from 0 to $1.3 \times 10^{6} \mathrm{ml}^{-1}$ at $7 \mathrm{wpi}$, course of infection experiment). The parasite load peaked at 6 to $7 \mathrm{wpi}$ in the course of infection and cohabitation experiments, and at 2 wpi in the susceptibility of 3 full-sib families experiment. The small inoculum (30000) did not produce external lesions in the susceptibility of 3 full-sib families study; the fish died (29 out of 30) before skin ulcers or exophthalmia could develop. It is not fully understood why there are such significant differences in susceptibility in Atlantic salmon to infection from the same parasite. Studies on the susceptibility of 17 families of Atlantic salmon to Cryptobia salmositica showed significant differences between families (Chin et al. 2002, 2004, Woo 2003). Variations in susceptibility to $S$. barkhanus in Atlantic salmon may have a genetic basis as was shown in cryptobiosis.

Acknowledgements. This study was supported by a grant from the Natural Sciences and Engineering Research Council (Canada) to P.T.K.W.

\section{LITERATURE CITED}

Archer RK (1965) Haematological techniques for use on animals. Blackwell, Oxford

Becker CD (1977) Flagellates parasites of fish. In: Kreier JP (ed) Parasitic Protozoa, Vol 1. Academic Press, New York, p 358-416

Chin A, Eldridge M, Glebe BD, Woo PTK (2002) Salmo salar and Cryptobia salmositica: variations in susceptibility and humoral response in families of Atlantic salmon to the pathogen. AquaNet II, Annual General Meeting, Moncton

Chin A, Glebe BD, Woo PTK (2004) Humoral response and susceptibility of five full-sib families of Atlantic salmon (Salmo salar L.) to the haemoflagellate, Cryptobia salmositica Katz 1951. J Fish Dis 27:471-481

Davis HS (1926) Octomitus salmonis, a parasitic flagellate of trout. Bull Bur Fish Wash 42:9-26

Ferguson HW (1979) Scanning and transmission electron microscopical observations on Hexamita salmonis (Moore, 1922) related to mortalities in rainbow trout fry Salmo gairdneri Richardson. J Fish Dis 2:57-67

Ferguson HW, Moccia RD (1980) Disseminated hexamitiasis in Siamese fighting fish. J Am Vet Med Assoc 177:854-857

Guo FC, Woo PTK (2004) Detection and quantification of Spironucleus barkhanus in experimentally infected Atlantic salmon Salmo salar. Dis Aquat Org 61:175-178

Islam AKM, Woo PTK (1991) Anemia and its mechanism in gold fish Carassius auratus infected with Trypanosoma danilewskyi. Dis Aquat Org 11:37-43

Kent ML, Ellis J, Fournie JW, Dawe SC, Bagshaw JW, Whitaker DJ (1992) Systemic hexamitid (Protozoa: Diplomonadida) infection in seawater pen-reared chinook salmon Oncorhynchus tshawytscha. Dis Aquat Org 14: 81-89

Kulda J, Lom J (1964) Remarks on the diplomastigine flagellates from the intestine of fishes. Parasitology 54:753-762

McFarland WN (1960) The use of anesthetics for handling and transport of fishes. Calif Fish Game 46:407-431

Molnar K (1974) Data on the 'Octomitosis' (spironucleosis) of cyprinids and aquary fishes. Acta Vet Acad Sci Hung 24: 99-106

Mo TA, Poppe TT, Iversen L (1990) Systemic hexamitosis in salt-water reared Atlantic salmon (Salmon salar L.). Bull Eur Assoc Fish Pathol 10:69

Moore E (1922) Octomitus salmonis, a new species of intestinal parasite in trout. Trans Am Fish Soc 52:74-97

Paull GC, Matthews RA (2001) Spironucleus vortens, a possible cause of hole-in-the-head disease in cichlids. Dis Aquat Org 45:197-202 
Poppe TT, Mo TA (1993) Systemic, graulomatous hexamitosis of farmed Atlantic salmon: interaction with wild fish. Fish Res 17:147-152

Poppe TT, Mo TA, Iversen L (1992) Disseminated hexamitosis in sea-caged Atlantic salmon Salmo salar. Dis Aquat Org 14:91-97

Poynton SL, Fraser W, Francis-Floyd R, Rutledge P, Reed P, Nerad TA (1995) Spironucleus vortens n. sp. from freshwater angel fish Pterophyllum scalare: morphology and culture. J Eukaryot Microbiol 42:731-742

Sano T (1970) Etiology and histopathology of hexamitiasis and an IPN-like disease of rainbow trout. J Tokyo Univ Fish 56:23-30

Sterud E, Mo TA, Poppe TT (1998) Systemic spironucleosis in sea-farmed Atlantic salmon Salmo salar, caused by Spironucleus barkhanus transmitted from feral Arctic char Salvelinus alpinus? Dis Aquat Org 33:63-66

Sterud E, Poppe TT, Bornø G (2003) Intracellular infection with Spironucleus barkhanus (Diplomonadida: Hexamitidae) in farmed Arctic char Salvelinus alpinus. Dis Aquat Org 56:155-161

Editorial responsibility: Wolfgang Körting,

Hannover, Germany
Thomas PT, Woo PTK (1988) Cryptobia salmositica: an in vitro and in vivo study on the mechanism of anaemia in infected rainbow trout, Salmo gairdneri Richardson. J Fish Dis 11: 425-431

Tojo JL, Santamarina MT (1998) Oral pharmacological treatments for parasitic diseases of rainbow trout Oncorhynchus mykiss. I: Hexamita salmonis. Dis Aquat Org 33: 51-56

Uldal A, Buchmann K (1996) Parasite host relations: Hexamita salmonis in rainbow trout Oncorhynchus mykiss. Dis Aquat Org 25:229-231

Woo PTK (1969) The haematocrit centrifuge technique for the detection of trypanosomes in blood. Can J Zool 47: 921-923

Woo PTK (2003) Cryptobia (Trypanoplasma) salmositica and salmonid cryptobiosis. J Fish Dis 26:627-646

Woo PTK, Poynton SL (1995) Diplomonadida, Kinetoplastida and Amoebida (phylum Sarcomastigophora). In: Woo PTK (ed) Fish diseases and disorders, Vol 1. Protozoan and metazoan Infections. CAB International, Wallingford, p 27-96

Submitted: March 30, 2004; Accepted: September 5, 2004

Proofs received from author(s): October 12, 2004 